\title{
Paraspinal muscle fibrosis: a specific pathological component in ankylosing spondylitis
}

\author{
R G Cooper, A J Freemont, R Fitzmaurice, S M Alani, M I V Jayson
}

\begin{abstract}
The histological appearance of percutaneous superficial paraspinal muscle biopsy specimens from eight patients with ankylosing spondylitis was compared with that of biopsy specimens from 13 control patients with similar degrees of disability and spinal immobility due to severe, chronic mechanical back pain. In both groups marked type II muscle fibre atrophy was shown. Additionally, in patients with ankylosing spondylitis there were obvious increases in perifibre connective tissue in association with central migration of cell nuclei but without evidence of inflammation. Qualitative electromyography failed to show denervation changes in either group. Paraspinal muscle fibrosis, occurring over and above atrophic changes due to disuse, seems to be a specific pathological component of ankylosing spondylitis which may be of particular importance in early disease as it may contribute towards back stiffness and weakness.
\end{abstract}

Pathological changes of the vertebral column are well documented in ankylosing spondylitis, but only limited studies have investigated whether the paraspinal muscles are affected by the disease process. The main finding of these studies was selective type II muscle fibre atrophy, ${ }^{1-6}$ but an excess of perifibre connective tissue was occasionally shown. ${ }^{25}$ Clearly, pathological changes in paravertebral muscles could have a considerable impact in ankylosing spondylitis as back mobilising physiotherapy has a major role in treatment regimens. Our study investigated further the pathological changes occurring in paraspinal muscles of patients with early and advanced ankylosing spondylitis and compared them with biopsy specimens from controls with chronic mechanical back pain to determine whether these changes were merely secondary to the spinal disease or due to a specific pathological process.

\section{Patients and methods}

Studies were made on eight male patients who fulfilled the New York criteria for definite ankylosing spondylitis ${ }^{7}$ and who were HLAB27 positive and rheumatoid factor negative. They were considered in two groups-four with early disease and mobile spines and four with advanced disease and immobile spines-to assess whether pathological changes were dependent on disease severity. Lumbar spinal flexion was assessed quantitatively by a modi- fied Schober's test, where the mean for men and women is $6-6.5 \mathrm{~cm},{ }^{8}$ and by measuring the finger to floor distance. Lumbar spinal extension was assessed semiquantitatively on a scale out of 3 where $0 / 3=$ no extension, $1 / 3=$ extension just possible, $2 / 3$ extension obvious but limited, $3 / 3=$ extension normal, $4 / 3=$ extension excessive, and $5 / 3=$ marked hyperextension. All of the immobile patients with ankylosing spondylitis had flexion deformities of the lumbar spine, with no visible extension, but all managed some degree of lumbar flexion.

These patients with ankylosing spondylitis were compared with 13 patients (six male, seven female) with severe chronic mechanical back pain despite previous laminectomy procedures. Both groups had severe functional impairment when assessed by questionnaire to rate chronic disability scores. ${ }^{9}$ The patients with back pain also had severe reduction of spinal mobility, hence their choice as 'controls' for comparison with the patients with ankylosing spondylitis. Any patients with spinal pain symptoms attributable to inflammatory, metabolic, or neoplastic causes, with clinical or radiological evidence of significant scoliosis $\left(>10^{\circ}\right)$ or who had ingested any agent capable of affecting skeletal muscle were excluded from the control group.

All subjects gave their informed consent for participation in this study, which was approved by Salford Health Authority ethical committee.

After clinical assessment of lumbar spine mobility both patients and controls underwent percutaneous superficial erector spine biopsy about $5 \mathrm{~cm}$ from the midline at the level of L3/4. The correct lumbar level was identified by palpation of the superior border of the iliac crest. The conchotome biopsy technique with asepsis and under local anaesthetic was used. ${ }^{10}$ Muscle samples were oriented immediately under the dissecting microscope and snap frozen in liquid nitrogen cooled isopentane. Cryostat sections were later prepared and stained with haematoxylin and eosin and histochemical sections prepared using both myosine ATPase at $\mathrm{pH} 9 \cdot 4^{11}$ and Mason's trichrome, the latter for visualising collagen. Immediately before biopsy patients with ankylosing spondylitis underwent venesection of serum for creatinine kinase estimation. Qualitative needle electromyography of superficial paraspinal muscles was also undertaken in six patients with ankylosing spondylitis and in six with chronic mechanical back pain to assess the possibility that myopathic or denervation/renervation changes were present. In addition, the paraspinal muscles and other spinal structures of 
five patients with ankylosing spondylitis were visualised radiographically in a single transaxial view obtained by computed tomography at the level of the upper vertebral end plate of $\mathrm{L} 4$.

\section{ANALYSIS}

Qualitative and semiquantitative histological interpretation of muscle biopsy specimens was provided by an experienced osteoarticular pathologist (AJF). Qualitative paraspinal elec-

Table 1 Group clinical details of mobile and immobile patients with ankylosing spondylitis and with chronic mechanical back pain. Results are given as means (SD)

\begin{tabular}{|c|c|c|c|}
\hline \multirow{3}{*}{$\begin{array}{l}\text { Clinical } \\
\text { variable }\end{array}$} & \multicolumn{3}{|c|}{ Patient groups and numbers } \\
\hline & \multicolumn{2}{|c|}{ Ankylosing spondylitis } & \multirow{2}{*}{$\begin{array}{l}\text { Chronic mechanical } \\
\text { back pain } \\
(6 M, 7 F)\end{array}$} \\
\hline & $\begin{array}{l}\text { Mobile } \\
(4 M)\end{array}$ & $\begin{array}{l}\text { Immobile } \\
(4 M)\end{array}$ & \\
\hline $\begin{array}{l}\text { Age (years) } \\
\text { Disease duration (years) } \\
\text { Schober's test (cm) } \\
\text { Finger-floor distance (cm) } \\
\text { Back extension }(\mathbf{n} / 3)^{*} \\
\text { Waddell disability index score }(0-9)\end{array}$ & $\begin{aligned} & 41 \cdot 3(13 \cdot 5) \\
& 12 \cdot 5(11 \cdot 8) \\
& 6 \cdot 5(2 \cdot 6) \\
& 14 \cdot 5(8 \cdot 2) \\
& 2 \cdot 3(1 \cdot 0) \\
& 2 \cdot 0(1 \cdot 6)\end{aligned}$ & $\begin{array}{l}54 \cdot 3(10 \cdot 8) \\
20.5(18 \cdot 5) \\
3.0(1.6) \\
39 \cdot 8(13.9) \\
0.0(0.0) \\
6.0(1.8)\end{array}$ & $\begin{aligned} 44 \cdot 2(5 \cdot 2) \\
7 \cdot 3(4 \cdot 2) \\
2 \cdot 4(0 \cdot 9) \\
48 \cdot 8(9 \cdot 2) \\
1 \cdot 2(0 \cdot 93) \\
7 \cdot 3(1 \cdot 3)\end{aligned}$ \\
\hline
\end{tabular}

*See 'Patients and methods'. tromyography was performed and interpreted by an experienced neurophysiologist (SMA). Statistical analyses were performed with the Mann-Whitney U test.

\section{Results}

Tables 1 and 2 show group clinical details of patients with ankylosing spondylitis and with back pain and table 2 gives the histological results of paraspinal muscle biopsies. The patient groups were of roughly similar age but patients with ankylosing spondylitis had a longer history of back symptoms. Lumbar mobility, except for extension in the immobile patients with ankylosing spondylitis, was clearly more restricted in the patients with chronic mechanical back pain, who also had more severe chronic disability index scores. Both in patients with ankylosing spondylitis and in those with back pain there was clear evidence of type II muscle fibre atrophy (fig 1). The ratio of type I to type II fibres was $2-10: 1$ in patients with ankylosing spondylitis (mean 4:1) compared with $1-5: 1$ in patients with back pain (mean 3:1). Histological evidence of fatty infiltration

Table 2 Individual clinical and histological details of mobile and immobile patients with ankylosing spondylitis and with chronic mechanical back pain

\begin{tabular}{|c|c|c|c|c|c|c|c|}
\hline $\begin{array}{l}\text { Patient } \\
\text { group and } \\
\text { sex }\end{array}$ & $\begin{array}{l}\text { Age } \\
\text { (years) }\end{array}$ & $\begin{array}{l}\text { Disease } \\
\text { duration } \\
\text { (years) }\end{array}$ & $\begin{array}{l}\text { Schober's } \\
\text { test } \\
(\mathrm{cm})\end{array}$ & $\begin{array}{l}\text { Finger-floor } \\
\text { distance } \\
(\mathrm{cm})\end{array}$ & $\begin{array}{l}\text { Back } \\
\text { extension } \\
(n / 3)\end{array}$ & $\begin{array}{l}\text { Waddell } \\
\text { disability } \\
\text { index score } \\
(0-9)\end{array}$ & Histology \\
\hline $\begin{array}{l}\text { AS } \\
\mathbf{M} \\
\mathbf{M} \\
\mathbf{M} \\
\mathbf{M}\end{array}$ & $\begin{array}{l}23 \\
52 \\
51 \\
39\end{array}$ & $\begin{array}{r}4 \\
25 \\
20 \\
1\end{array}$ & $\begin{array}{l}8 \\
9 \\
6 \\
3\end{array}$ & $\begin{array}{r}21 \\
9 \\
6 \\
22\end{array}$ & $\begin{array}{l}3 \\
1 \\
3 \\
2\end{array}$ & $\begin{array}{l}2 \\
0 \\
4 \\
2\end{array}$ & $\begin{array}{l}\text { Type II atrophy. Minimal fibrosis } \\
\text { Minimal fibrosis } \\
\text { Type II atrophy. Fatty infiltration } \\
\text { Gross fatty infiltration }\end{array}$ \\
\hline $\begin{array}{l}\text { AS (immobile) } \\
\mathbf{M} \\
\mathbf{M} \\
\mathbf{M}\end{array}$ & $\begin{array}{l}66 \\
49 \\
60 \\
42\end{array}$ & $\begin{array}{r}46 \\
4 \\
10 \\
22\end{array}$ & $\begin{array}{l}3 \\
3 \\
1 \\
5\end{array}$ & $\begin{array}{l}52 \\
41 \\
46 \\
20\end{array}$ & $\begin{array}{l}0 \\
0 \\
0 \\
0\end{array}$ & $\begin{array}{l}4 \\
8 \\
5 \\
7\end{array}$ & $\begin{array}{l}\text { Gross type II atrophy with fat and fibrosis } \\
\text { Gross type II atrophy with severe fibrosis } \\
\text { Gross type II atrophy with severe fibrosis } \\
\text { Gross type II atrophy with fat and fibrosis }\end{array}$ \\
\hline $\begin{array}{l}C M B P^{*} \\
\mathbf{M} \\
\mathbf{M} \\
\mathbf{M} \\
\mathbf{M} \\
\mathbf{M} \\
\mathbf{M} \\
\mathbf{F} \\
\mathbf{F} \\
\mathbf{F} \\
\mathbf{F} \\
\mathbf{F} \\
\mathbf{F} \\
\mathbf{F}\end{array}$ & $\begin{array}{l}49 \\
36 \\
43 \\
44 \\
49 \\
46 \\
52 \\
46 \\
44 \\
39 \\
49 \\
43 \\
35\end{array}$ & $\begin{array}{r}9 \\
2 \\
7 \\
15 \\
4 \\
3 \\
4 \\
8 \\
14 \\
3 \\
8 \\
7 \\
11\end{array}$ & $\begin{array}{l}3 \\
3 \cdot 5 \\
2 \\
2 \\
1 \cdot 5 \\
4 \cdot 5 \\
2 \\
2 \\
2 \cdot 5 \\
1 \cdot 5 \\
2 \\
2 \\
3\end{array}$ & $\begin{array}{l}50 \\
32 \\
50 \\
62 \\
59 \\
43 \\
43 \\
55 \\
44 \\
60 \\
56 \\
42 \\
39\end{array}$ & $\begin{array}{l}0 \\
3 \\
2 \\
1 \\
1 \\
3 \\
1 \\
1 \\
1 \\
1 \\
1 \\
0 \\
1\end{array}$ & $\begin{array}{l}8 \\
5 \\
8 \\
7 \\
7 \\
7 \\
6 \\
6 \\
7 \\
9 \\
9 \\
9 \\
7\end{array}$ & $\begin{array}{l}\text { Type II atrophy } \\
\text { Type II atrophy } \\
\text { Normal } \\
\text { Type II atrophy } \\
\text { Normal } \\
\text { Type II atrophy } \\
\text { Type II atrophy } \\
\text { Type I atrophy. Neuropathic (?) (EMG* not done) } \\
\text { Marked fatty infiltration } \\
\text { Type II atrophy } \\
\text { Marked type II atrophy } \\
\text { Type II atrophy with fatty infiltration } \\
\text { Type II atrophy with fatty infiltration }\end{array}$ \\
\hline
\end{tabular}

${ }^{*} \mathrm{AS}=$ ankylosing spondylitis; $\mathrm{CMBP}=$ chronic mechanical back pain; $\mathrm{EMG}=$ electromyography.
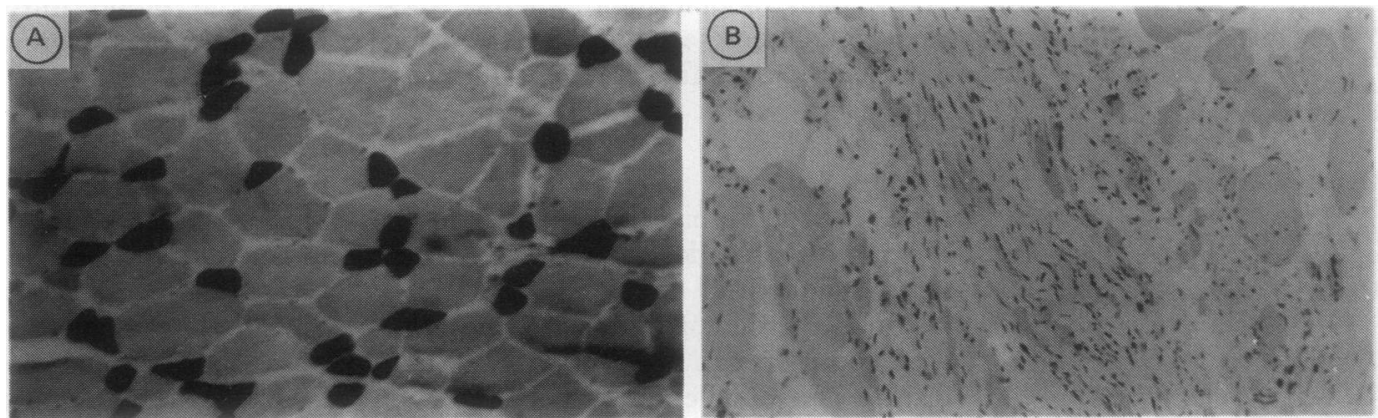

Figure 1 Transverse sections of paraspinal muscle from patients with ankylosing spondylitis showing $(A)$ a biopsy specimen stained with ATPase at pH 9.4; type II (darkly stained) fibres are clearly atrophic in early ankylosing spondylitis, as also seen in patients with chronic mechanical back pain and $(B)$ biopsy specimen stained with haematoxylin and eosin, exuberant fibrosis with central migration of nuclei in advanced ankylosing spondylitis. 

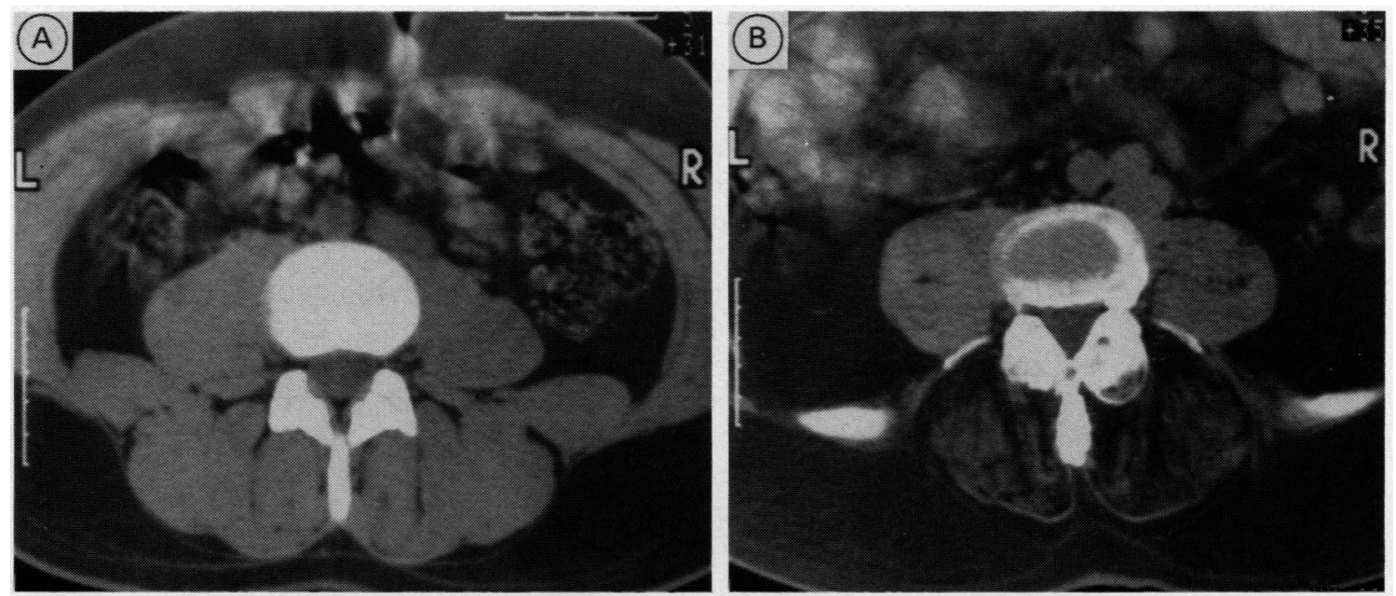

Figure 2 Computed tomographic scans through the upper table of L4 in patients with ankylosing spondylitis with $(A)$ mobile and $(B)$ rigid spines. Gross, bilateral paraspinal muscle atrophy with fatty replacement is shown in the patient with the rigid spine, whereas the appearance is relatively normal in the patient with the mobile spine.

was present in both patient groups but was more marked and sometimes dramatic in ankylosing spondylitis, as confirmed by computed tomography (fig 2). In addition, in most patients with ankylosing spondylitis there was clear histological evidence of perifibre and periseptal infiltration with fibrous connective tissue (fig 1). The degree of fibrosis varied according to the severity of spinal disease, being greatest in the patients with the most rigid spines, though fibrosis was present even in patients with fully mobile spines (table 2). In those biopsy specimens where fibrosis was most marked there was also evidence of internalisation of muscle cell nuclei (fig 1). There was no evidence of increased fibrosis in any of the muscle biopsy specimens from patients with chronic mechanical back pain. The histological abnormalities in ankylosing spondylitis were not associated with inflammatory cell infiltration or with skeletal muscle enzyme abnormalities, serum creatine kinase being less than $190 \mathrm{IU} / 1$ in all subjects. Qualitative electromyography showed no abnormality in either group of patients.

\section{Discussion}

Inflammation or effusion within a joint, even in the absence of pain, can cause reflex inhibition of the muscles controlling that joint. ${ }^{12-14}$ The resulting weakness may render the joint less stable and therefore liable to further damage. ${ }^{14}$ This is most obvious in the knee, when synovitis may lead to quadriceps weakness and wasting and joint instability. Whether the spinal pain and inflammation which occur in ankylosing spondylitis might impair paraspinal muscle activation by similar reflex inhibition is unknown. The findings of type II paraspinal muscle fibre atrophy in patients with ankylosing spondylitis and in those with chronic mechanical back pain provides indirect evidence that in both groups motor activation has been reduced. It was not possible, however, to determine whether this resulted from simple disuse due to pain on movement, or from reflex inhibition.

The histological appearance of normal paraspinal muscles is poorly recorded in limited cadaveric studies. ${ }^{15} 16$ These indicate that type I and II fibres are of roughly equal size but with a distribution that favours type I fibres slightly, type I:type II fibre ratios being $1 \cdot 2-1 \cdot 4: 1$. The present finding of mean ratios of $3: 1$ and $4: 1$ for patients with back pain and ankylosing spondylitis respectively, together with minor to marked type II fibre atrophy, presumably indicates type II fibre loss as a consequence of the reduced motor activation. Previous histological investigations of paraspinal muscles in ankylosing spondylitis ${ }^{1-6}$ showed, in addition to the selective type II fibre atrophy, type I fibre changes in the form of 'moth-eaten' and 'targetoid' fibres on NADH-diaphorase histochemical preparations. ${ }^{4-6}$ As these type I fibre changes are not specific for ankylosing spondylitis the NADH-diaphorase staining technique was not used in this study. Electron microscopy studies of paraspinal muscle in ankylosing spondylitis have shown marked structural disruption with $\mathrm{Z}$ band streaming, loss of myofilamentous alignment, loss or absence of mitochondria, abnormalities of the basement membrane, and the presence of abnormal lipid and nemeline inclusion bodies. ${ }^{4-6}$ Such abnormalities also occur in congenital structural myopathies, where renervation follows denervation and where muscles are under reduced tension-for example, because of tenotomy. ${ }^{17} \mathrm{It}$ is believed that a necessary stimulus for accurate expression of synthetic muscle enzymes is tension, without which muscle disorganisation can occur. ${ }^{6}$ Loss of spinal movement, as in advanced ankylosing spondylitis or severe chronic mechanical back pain might, perhaps, lead to this. The early interpretations of the histological abnormalities in ankylosing spondylitis were of simple disuse atrophy, but neurogenic mechanisms were subsequently proposed, with damage to the posterior branches of the spinal nerves arising owing to bony encroachment by pathological apophysial joints in exit foramina. ${ }^{5}$ Only one previous study undertook paraspinal electromyography, the results showing only minor evidence of denervation. ${ }^{3}$ The lack of any electromyographic evidence for denervation or renervation in the current study 
seems to exclude significant nerve root compression as a cause of the noted histological changes. Furthermore, if neurological damage had been occurring then, by chance, it should presumably have resulted in type I and II fibre changes of roughly similar degree. This was not the case in this or previous studies. Neurological damage to motor nerves causes muscle fibre wasting and angulation with evidence of fibre renervation, including fibre-type grouping. ${ }^{17}$ The marked predilection for type II fibre atrophic changes in ankylosing spondylitis and chronic mechanical back pain, without evidence of fibre-type grouping, therefore suggests reduced activation and not denervation.

In previous histological studies where paraspinal muscle fibrosis in ankylosing spondylitis was occasionally shown ${ }^{2} 5$ it was suggested that such an abnormality was non-specific and secondary to disuse or denervation. Patients with ankylosing spondylitis were not compared with 'control' subjects, however, to validate such claims, hence our use of patients with chronic mechanical back pain who actually had a greater degree of immobility and functional impairment than that seen in the patients with ankylosing spondylitis. Such a comparison showed striking differences in the pathological appearance of paraspinal muscle in the two groups-namely, the presence of excessive perifibre and periseptal fibrosis in patients with ankylosing spondylitis. This was not seen in patients with back pain. These findings cannot be explained by differences in spinal mobility or the severity of histological changes alone as the type II fibre atrophy and fatty infiltration were of a similar extent in both groups of patients. Furthermore, the fibrosis in ankylosing spondylitis occurred even in patients with almost fully mobile lumbar spines, who had only minor type II fibre atrophy. Disease duration, and therefore potential duration of spinal immobility, was in general greater in patients with ankylosing spondylitis, but it was apparent that paraspinal fibrosis occurred even where disease duration was obviously less than the mean duration of $7 \cdot 2$ years in patients with chronic mechanical back pain. These results strongly suggest that paraspinal muscle fibrosis in ankylosing spondylitis is a specific pathological process.

In normal muscle a few isolated collagen fibrils can be seen by electron microscopy between fibres-in the endomysium. Minor increases in endomysial collagen and connective tissue occur with advancing age ${ }^{18}$ and immobilisation, ${ }^{19}$ but marked increases usually occur only in certain circumstances-notably, after prolonged denervation with advanced atrophy ${ }^{20}$ and after myofibre destruction in muscular dystrophy and inflammatory myositis. ${ }^{21} 22$ Extensive fibrosis can occur where muscle fibre damage is minimal-for instance, in the rare 'rigid spine' syndrome. This affects male children causing marked limitation of the dorsolumbar spine. Paraspinal electromyography shows a myopathic pattern, whereas histology shows excess cellularity, marked perimysial and endomysial fibrosis, replacement of muscle by connective tissue, and central migration of nuclei. ${ }^{23}$ These histological abnormalities seem remarkably similar to those presently described in ankylosing spondylitis. As collagen, the chief component of fibrous connective tissue, has a low compliance even small increases could cause considerable muscle stiffness. ${ }^{18}$

A further histological difference between the patient groups in the current study was the presence of internalised nuclei in the paraspinal muscle of patients with ankylosing spondylitis. Central migration of nuclei is a well recognised, but non-specific, feature of various myopathic processes. These could cause muscle cell damage or death, with characteristic electromyography and serum creatine kinase changes, and previous studies showed raised enzyme concentrations in some patients with ankylosing spondylitis, ${ }^{24}$ but neither of these abnormalities was recorded in the present study. Possible explanations for these apparent discrepancies are that any myopathic process in ankylosing spondylitis is patchy, and hence liable to electromyography sampling error, or of either low or variable intensity, such that enzyme activity could be normal. It was previously suggested that muscle fibrosis in ankylosing spondylitis might represent the end point of an inflammatory myopathic process. ${ }^{25}$ Although this may be the case, this study and others have consistently shown that histological paraspinal muscle abnormalities in ankylosing spondylitis occur without obvious inflammation. The cause of muscle abnormalities is therefore unknown, but a process similar to enthesitis has been proposed. 5

Muscle abnormalities are not limited to the paraspinal muscle in ankylosing spondylitis as type II fibre wasting and central migration of nuclei have been shown in quadriceps femoris, which have also been shown to be weak. ${ }^{25}$ Furthermore, a mild diffuse increase of interstitial connective tissue has been demonstrated in myocardial tissue obtained from patients with ankylosing spondylitis at necropsy. ${ }^{26}$ It thus seems that ankylosing spondylitis is associated with a generalised muscle problem. Paraspinal muscle atrophy with fibrosis is likely to contribute towards the spinal weakness and stiffness experienced by patients with ankylosing spondylitis, adding to that resulting from pathological changes occurring in the spine. By reducing the strength of the paraspinal muscles, such abnormalities may severely hamper mobilising physiotherapy and may well hasten the process of vertebral ankylosis.

1 Aufdermaur M. Anatomic pathologique de la spondylite ankylosante. Acta Rheumatologica 1954; (2): 60.

2 Pohl V W, Sievers B U. Veranderungen der musculatur bei spondylitis ankylopoetica. $Z$ Rheumatol 1974; 33: 249-53.

3 Roux H, Serratrice G, Maestracci D, et al. Les atteintes musculaires au cours de la pelvispondylite rheumatismale. Rev Rheum Mal Osteoartic 1975; 42: 231-8.

4 Berman L, Isaacs H, Pickering A. Structural abnormalities of muscle tissue in ankylosing spondylitis. S Afr Med $\mathcal{F} 1976$; 50: $1238-40$.

5 Carraba M, Chevallard M, Colombo B, Dworzak F, Mora M, Cornelio F. Muscle pathology in ankylosing spondylitis. Clin Expt R heumatol 1984; 2: 139 -44.

6 Kukulas B A, Morrison I, Owen E T, Kitridou R. Unusual paraspinal muscle lesions in ankylosing spondylitis. Clin Exp Rheumatol 1987; 23: 23-9.

7 Bennett P H, Wood P H N, eds. Population studies of the rheumatic diseases. Amsterdam: Excerpta Medica, 1968: 456-8. (International congress series.) 
8 Moll J M H, Wright V. Normal range of spinal mobility. An objective clinical study. Ann Rheum Dis 1971; 30: 381-6.
Waddell G, Main C J. Assessment of severity of low-back disorders. Spine 1984; 9: 204-8.

10 Dietrichson P, Coakley J, Smith P E M, Griffiths R D, Helliwell T, Edwards R H T. Conchotome and needle percutaneous biopsy of skeletal muscle. F Neurol Neurosurg Psychiatry 1987; 50: 1461-7.

11 Round J M, Matthews Y, Jone D A. A quick, simple and reliable histochemical method for ATP-ase in human muscle preparation. 7 Histochem 1980; 12: 707-10.

12 De Andradre J R, Grant C, Dixon A St J. Joint distension and reflex muscle inhibition in the knee. $\mathcal{F}$ Bone foint Surg aAm] 1965; 47: 313-22.

13 Baxendale R H, Ferrell W R, Wood L. Knee joint distension and quadriceps maximal voluntary contraction in man. and quadriceps maximal

14 Stokes $M$, Young A. The contribution of reflex inhibition to arthrogenous muscle weakness. Clin Sci 1984; 67: 7-14.

15 Johnson M A, Polgar J, Weightman D, Appleton D. Data on distribution of fibre types in thirty-six human muscles. An autopsy study. $₹$ Neurol Sci 1973; 18: 111-29.

16 Polgar J, Johnson M A, Weightman D, Appleton D. Data on fibre size in thirty-six human muscles. An autopsy study. I Neurol Sci 1973; 19: 307-18.

17 Cancilla $P$ A. General reaction of muscle to injury. In: Heffner $\mathbf{R}$ R, ed. Contemporary issues in surgical pathology. vol 3. Muscle pathology. New York: Churchill Livingstone, 1984: 15-30.

18 Alnaqeeb M A, Al Zaid N S, Goldspink G. Connective tissue changes and physical properties of developing and ageing skeletal muscle. F Anat 1984; 139: 677-89.

19 Williams P E, Goldspink G. Connective tissue changes in immobilised muscle. F Anat 1984; 138: 343-50.

20 Tomanek R J, Lund D D. Degeneration of different types of skeletal muscle fibres. I. Denervation. $\mathcal{f}$ Anat 1973; 116: 395-407.

21 Duance V C, Stephens H R, Dunn M, Bailey A J, Dubowitz V. A role for collagen in the pathogenesis of muscular dystrophy? Nature 1980; 284: 470-2.

22 Duance V C, Black C M, Dubowitz V, et al. Polymyositisan immunofluorescence study on the distribution of collagen types. Muscle Nerve 1980; 30: 487-90.

23 Dubowitz $\mathrm{V}$ Muscle disorders in childhood. Philadelphia: Saunders, 1978: 239-43.

24 Calin A. Raised serum creatine kinase activity in ankylosing spondylitis. Ann Rheum Dis 1975; 34: 244-7.

25 Hopkins G O, McDougall J, Mills K R, Isenberg D A Ebringer A. Muscle changes in ankylosing spondylitis. $\mathrm{Br} \mathcal{f}$ Rheumatol 1983; 22: 151-7.

26 Brewerton D A, Gibson D G, Goddard D H, et al. The myocardium in ankylosing spondylitis. A clinical, echocardiographic and histopathological study. Lancet 1987; i: 995-8. 